In this situation, the frontline agent translates, through a process of valuation between the private, youthful lifeworld reality of a person and more public forms of justification that aim at validity in the regime of justified action. Starting from familiar attachments, a person is constructed that can respond to more "public" forms of justification as enshrined in the job interview. Little by little - starting from private aspects of the person (practicing a sport in a club) - other forms of valuation are activated (for instance being able to work with people you do not like - the domestic order of worth, being on time - the industrial order of worth). Based on attachments in the close sphere that a person is constructed that becomes intelligible within the frameworks of the labor market. On the level of valuation and of attribution of competences, a "mediation" between the logic of valuation of employers and the "competence" of the person takes place. The frontline agent acts as an "intermediary" (Diaz-Bone 2015: 11). Backed by different quality conventions, he relates the different logics of valuation and creates a situated compromise between them. In this case, the SeMo acts as a "compromising device" (Thévenot 2001: 411) between different logics of valuation that one finds in its organizational environment. Second, in this process, the frontline agents propose adequate and situatively appropriate vocabularies of motives, of ways of displaying oneself, of ways of talking about oneself that make it possible for the young person to potentially become intelligible and recognizable in the public tests of the labor-market (see e.g. Dahmen 2019). This form of pedagogical accompaniment that this process of compromising implies operates (as described in chapter 6.2.3) with a temporary suspension of the official convention-based evaluative horizons (Breviglieri/StavoDebauge 2007). It is only by acting "below the conventions" (ibid.), by temporarily suspending the evaluative frameworks of the labor-market that the young person becomes visible as a person with specific life-world attachments that then can be harnessed for the fashioning of viable integration narratives that potentially withstand the evaluation criteria of the labor market.

\title{
6.5. "Making Up" Viable Future Selves Through Evaluation - Working with the Portfolio-Tool
}

The follow up of a young person usually starts with a standardized assessment of school competencies and a psychometric assessment of competencies and career choice. Usually, these psychological aptitude tests are deployed by a professional guidance psychologist in smaller groups. Thereupon, each young person receives individual feedback on his test results where both the psychologist as well as the personal counselor of the participant assist and where a discussion on possible professional pathways are discussed. The subsequent institutional work is documented in a fifty-page "portfolio"-tool which is gradually completed during the in- 
take process period in the Motivational Semester, and which mainly consists of selfassessment questionnaires on personal competencies, capacities, and job preferences. This "portfolio-tool" has a pivot function between the rather administrative aspects and the concrete practices: Firstly, the same document is used in all Motivational Semesters of the cantons, its mandatory use is fixed in the provision agreement ${ }^{8}$. The portfolio is thus a standardised artefact that potentially gives insight in the internal organization of the Motivational Semester. As its use is mandatory it constitutes a "hinge" between the local case-based practices and extra-local political rationalities. Just like the document of the sanctioning described earlier, this document serves to align - trough it's replicability in a multitude of contexts - to "coordinate people's doings translocally" (Smith 2005: 166): On the one side, the doings of frontline agents in the different Motivational Semesters with the rationalities of the active-labor market policies of the state, but also the doings of young persons with the organisational goals of the Motivational Semester. As a "standardized artifact" (Wolff 2004: 284), the portfolio-document bears institutional traces that allow making inferences on the activities, intentions, and considerations of the creators of the document as well as their institutional identities and their interests. The portfolio-document is an "active agent in networks of action" (Prior 2008: 822), as a socio-material object (Schatzki 2001) it potentially mediates, configures and guides institutional practice. It has specific action programs inscribed in it (Akrich/Latour 1992: 259) highlights potentially institutionally relevant categories and invites to specific forms of description (Gubrium et. al 1989: 197), and offers through its construction a specific way of using it and highlights specific local doings and saying as an "institutionally actionable" (Smith 2005) reality. Nevertheless, the portfolio as an artifact does not unilaterally define practice. Rather, as research on medical records has shown, it has the potential to impact and transform social interaction while being "continually subordinated to the contingent requirements of the actual tasks" (Berg 1996: 501). The following analysis does not look at the concrete use of the document "in action" but focusses on its programmatic and institutional traces. Even without an ethnomethodological turn-for turn analysis of the in-situ use of the document, it is possible to analyze the potential of the portfolio to prefigure specific practices and to evaluate its function within the larger workings of the institution. A specific focus will be put on the ways it positions the

8 As described in the Provision agreement for SeMo by the cantonal authority of employment measures the Motivational Semesters should provide a targeted Intervention that allows "An individual assessment about the participants' personal, family and school/professional situation/ A professional plan taking into consideration their interests", and a "balance between these plans and the competences of the participants by means of confrontation to the realities in the labor market". The use of a basic version of the mentioned Portfolio-document is mandatory. One of the official goals is thus to help the young participants to perform a "realistic and realisable" professional choice. 
participants. Large parts of the document are designed to be completed alone or in (guided) group sessions. In addition, the documents contain a sort of trivialized career guidance test that is to be filled in individually. This character of the portfolio suggests focusing on the ways in which the young persons are positioned in the instructions and through the construction of the document. As such, the analysis will ask for the implicit and articulated "norms of recognizability and linguistic positioning" (Reh/Ricken 2012: 44, own translation), respectively the different "orders of worth" (Boltanski/Thévenot 1999) that guide the evaluation devices and lead them to attribute "greatness" or "smallness" to people in the light of these criteria. The latter constitute the normative grounding of the practical exercises and tests, the technical instructions, in the invocations and accentuations of the document: What are norms of suitable behavior? What visibilities are created through the document? What characteristics are made "institutionally" actionable? What kind of subject-positions are made intelligible in the document?

\subsubsection{Elements of the Portfolio}

The portfolio is a fifty-page document that every participant receives when entering the Motivational Semester. While many parts of the document are to be completed in individual sessions by the young participant, the portfolio is put in a personalized folder (containing, visible on the outsider, the name of the participant) that is stored in the office of the personal counselor of the young person. The young person has access to his folder on request, it is also used in group settings (for instance when collectively filling out a form that figures in it). This material dimension of the portfolio shows that is has a hybrid function: on the one side, it is directly at the hand of the individual counselor who can have all information on the progress of a case at a glance. In addition, as the young persons are asked to file all documents related to their job search activities in this portfolio, the counselor can evaluate and control the young person at a glance. On the other side, the portfolio contains roughly two-thirds of standardized self-evaluation texts and worksheets, in which young persons are asked to evaluate themselves according to descriptive criteria, to judge their scholarly abilities (and to rate them according to a traffic light system) or to write down potential job interests. The portfolio also contains evaluation questionnaires that are filled out by employers and the heads of the different workshops that the young participants participate in. The latter often contain tables with lists of different competencies and a likert-scale numeric evaluation scale ranging from green (best) to red (worst). They usually comprise a possibility for young people to self-evaluate their competencies. 


\subsubsection{Linking the administrative-temporal order of the Motivational Semester with practices of Self-Exploration}

The first page of the portfolio is a kind of progression chart that describes different activities as a sequence of separated but interrelated activities. It is at the same time a table of contents that orders the portfolio using numbers (1-5) and different colors (red-blue). It describes different steps in a linear manner as a kind of action plan that starts with a competency assessment (1), career orientation (2) an evaluation report (3) and an action plan (4).

Figure 3 and 4: Portfolio Tool: "Progress Chart" (left) and "Checklist" (right)

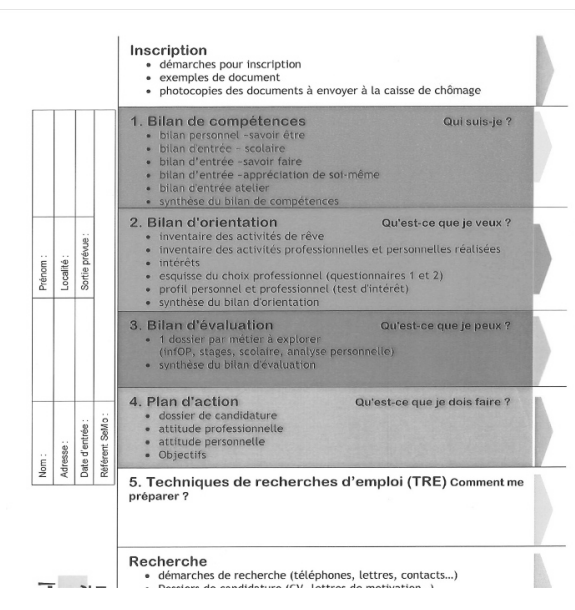

Check-list

\begin{tabular}{|c|c|c|}
\hline \multicolumn{3}{|c|}{ Bilan de compostences > senv. I moís } \\
\hline 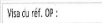 & Bi.zn persomel & Dore: \\
\hline Ysadeffit of: & Bi.an scclaire c'entrée & Dare: \\
\hline Visentef of : & Bian d'ateleierssid'entrée & Dore: \\
\hline Viscout tot of : & Syrthèse du bilan de corpésences & Dare: \\
\hline Biland'orientation & senv. 1 1 nois & \\
\hline 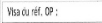 & Inventaire des activités professionneles de rêve & Daxe: \\
\hline Viscoutet of : & Inventaire des activités pers, ex proi, réaisises & Laxe: \\
\hline Vogdrét. of : & | Interêts & Dà̃e: \\
\hline Viscoutet of : & Esquisse duchoix professionel 1 \& 2 & Daxe: \\
\hline Viscoutet. op: & Test tîntérề: Bilan professionrel & Dâte: \\
\hline Wascuct of : : & Eraluation du test dintefíts & Date: \\
\hline Vistoure of: & Synnhesese du bilan c'orientation & Date: : \\
\hline Biland'evaluation & 2eny. J nools & \\
\hline Wisductef op : & Ouverture d'un dossier d'explaration pa métier & Date: \\
\hline Wisdu ié. op : & Evaduation des métiers explorés & Date: \\
\hline Ysadou tif op: & Syntheses du bilan o'éraluation & Date: \\
\hline
\end{tabular}

Each of the 4 points lists sub-elements of the portfolio and are exemplified by a question (1: Who am I?, 2: What do I want?, 3: What am I able to do...). The young persons are described as "seekers": an adequate action plan for one's own professional future requires adequate knowledge on oneself, it presupposes thus that the young persons do not (yet) adequately know themselves. The questions figuring on the right side of the document display the process of choosing one's profession as a linear process of self-exploration that is composed of adequate self-knowledge, knowledge on one's own preferences and wishes as well as adequate knowledge on "what I am able to do". On the left corner of the document, a box foresees some space for the name of the participant, the date, the name of the individual counsellor, the date of entry and the "foreseen date of exit" from the Motivational Semester. These dates mark the time period in which the portfolio is meant to be worked on. The mentioning of these dates as well as the name of the individual counselor introduces a temporal order in which points 1-4 are meant to be executed and allocates 
a personal counselor (Réferent). Both elements introduce the document within an institutionalized framework. Participation in the Motivational Semesters is usually granted for an exact period of 6 months. As the next page shows, the portfolio foresees an exact time plan for the execution of the different tasks that figure in it. The checklist displays the different elements of the portfolio in the form of a chart that shows precise timelines for the different elements. For instance, the competency assessment is expected to be completed in one month. The box leaves extra space for a date of execution and for each smaller step, the signature of the individual counselor. The document seems rather to address the personal counselor who, through this document, is assigned a supervising authority for the timely execution of the tasks figuring in it. In addition, this part of the document introduces a clear temporal order of activities and links the execution of these activities to a timeline. One can expect that the everyday use of this document amounts to a progress report, the document ensures that the personal counselor keeps track of the progress of the participant. In addition, each of the colored steps is finalized in a synthesis (the fields with the grey background) in which the participant is asked to write up the previous results. The document seems to bear witness of an effort to synchronize the self-exploration activities of the participants with the temporal order of the measure, through linking different steps of an idealized job-search process with the 6 month-timeline of the Motivational Semester. The temporal inscriptions of the analysed form have a special relevance from the background of the subjective biographical dimension of transitions. On the level of the subject transitioning from school to work, comes with the social requirement to "to construct positive forms of relationships between their own time of life and social time" (Leccardi 2008: 124). The form, through the manifold temporal references and inscriptions creates a link between the social organisation of time (duration of the measure, date of entry, which themselves are dependent on the temporal organisation of schooling according to school terms and semesters), and the activities performed in the Motivational Semester that aim at fostering a specific, planificatory posture towards one's own biography on the side of the participants.

\subsubsection{Individual Self-Exploration and the Invocation of Individuality}

The cover sheet of the first section (red - the "competency check") of the portfolio document carries the phrase "every project is constructed from foundations - your personality, your interests, your school achievements, and your life experiences. This is what makes your particularity and provides you with the feeling of being unique" (portfolio document, p. 11.). This first sentence describes job choices as an individual self-project. Job choice is rooted in individual dispositions and characteristics, it is an expression of one's own individuality and is an important element of authenticity ("being unique"). This resonates within the "inspirational city" (or 
order of worth) in which greatness or high status pertains "the saint who achieves a state of grace or the artist who receives inspiration [...] It reveals itself in inspired manifestations (holiness, creativity, artistic sense, authenticity, etc.) (that) constitute the privileged form of expression" (Boltanski/Chiapello 2007: 25). Job choice is framed above all as expressions of one's own unique dispositions and authenticity. This quote positions young people as "inspired" job searchers who strive towards the realization of their innate potentials to create. The notion of "project" is an important datum of this section. The phrase (as well as the whole construction of the portfolio) starts from the supposition that young people do - at least until now lack knowledge about their potentialities, their capacities and the unique features that every person disposes of but that first have to be discovered. The grammar of the individualized self-project resonates with the idea of biographical self-construction in the era of individualization, in which a person learns to "conceive of him or herself as the center of action as the planning office with respect of his/her own Biography" (Beck 1992: 135). The positioning of the participant as a choosing individual driven by the desire for self-realization appears contradictory considering that many structural factors clearly limit the space of possible apprenticeships. Nevertheless, the absence of mentioning such structural factors in the first part of the portfolio, as well as the high emphasis put on personal autonomy, does not mean that there is an absence of power. On the contrary, the autonomy of the self is both objective and instrument of governmental rule in liberal democratic societies. Here power is productive rather than simply restrictive: "it provides individuals with new rationales and procedures for living their lives according to a regime of choice, and for governing themselves within an environment that offers a plurality of possible styles of life, and in which individual fate is recast as the outcome of personal acts of choice" (Rose 1998: 93). In the light of a plurality of lifestyles and possibilities and a necessary indifference of liberal democratic societies towards them, the governmental rule requires individuals to understand themselves as choosing, autonomous subjects. Tools such as the portfolio provide vocabularies of motives and narrative templates for self-construction, they provide (discursive) resources for conceiving oneself $s$ a choosing subject. On the other side, if young people understand their potential future Job as an outcome of personal acts of choice, they are at the same time invoked as responsible for it. The grammar of the individual self-project leaves no spaces for structural explanations of your own fate. Failure can only be attributed to the individual.

\subsubsection{Self-Assessments as Tools for Self-Discovery}

The first work-sheet of the portfolio contains a personal self-evaluation form. The document shows a self-assessment questionnaire in which young people are invited choose from a list of thirty qualifying adjectives ("active, adaptable, analytic, 
communicative..") and young persons are invited to "read them out loud and ask yourself to what extent they correspond to your personality". A second page lists a number of activities grouped according to domains ("needle-work, sewing, knitting, cultivation of flowers: Use my hands, calculating a budget, doing an inventory, write a text, use a personal computer: administrate, organize, planify, a.s.o."). The participants are asked to evaluate to what extent they master them. This tool invites young persons to inner dialogue about themselves. They are asked to reflect on themselves in the light of a list of pre-given items. Most importantly, the document invites to "choose" among items, the choice of some items is mutually exclusive ("shy" vs. "confident"). This means that young people will have to choose in a binary manner between adjectives that are deemed to qualify the whole "personality". In addition, they refer to the person as a "whole" (no space is left for the possibility of being shy in some moments, bold in some others). The abstraction from situational expression of personal characteristics allows naturalizing these adjectives as expressions of the "whole" personality with congruent characteristics over time. In addition, the adjectives to choose from are not selected randomly, they rather remind a partly overstated, excessively positive vocabulary that reminds the vocabulary of job applications, it reflects a descriptive vocabulary that is normatively loaded with the requirements of the labor market. Young people are thus confronted with descriptive vocabulary and asked to apply it to themselves in a reflexive manner. The "norms of recognizability and linguistic positioning" (Reh/Ricken 2012) articulated in the document strongly reflects the evaluative frameworks of the labor market, the document opens up a discursive space in which each and every one is asked to position oneself, from the background of norms of intelligibility of the labor market. This has potentially subjectivating effects, as the document addresses young people regarding the question if their personality corresponds evaluative frameworks of the labor market. Participants learn, similarly to learning a new language, a vocabulary of self-description that makes them intelligible in the recognition orders of the labor market.

\subsubsection{Panoptical Evaluation and Self-Improvement}

A third document, the evaluation tool for the workshop provides a standardized list of different domains (professional competencies, personal competencies, relational competencies). Both the young person and the workshop leader are asked to evaluate on a four-point scale if the participant is for instance "able to follow the instructions, understands them, has an appropriate working rhythm, is orderly and cleanly". A similar document exists for each internship a young person does during his stay at the Motivational Semester. This form is to be re-evaluated in regular time spans and the results of the evaluations are discussed during the regular counseling meetings. The constant use of such forms establishes a mode 
of panoptical evaluation, where different persons (the workshop foreman, different employers, the counselor) establish a space of observation (Kelle/Schmidt 2017), in which the behavior of the young person is constantly evaluated. The document streamlines the observation of concrete doings and beings towards those characteristics that highlight operative functionality in the context of a firm. They constitute a specific space of evaluation that delimits the intelligible self-descriptions that are proposed to young people as templates for self-construction. As a kind of "recognition orders" these criteria define the space of doings and sayings that correspond to the functional requirements and the norms of suitable behavior of the small, production-oriented firm that in Switzerland constitutes the main provider of apprenticeships. Strictly speaking, the characteristics defined in the left column are not competencies in the narrow sense - no reference is made to specific, sectorrelated knowledge, or to general capacities (e.g. maths, writing). The characteristics rather describe dispositions and habits (disponibility, will to integrate in a new working environment, proactiveness, working rhythm) that are quite blurry descriptions and that leave ample space for interpretation (and requires no further explanation) on the side of the person evaluating them. This makes up their panoptical character - the space of observation does work without constant surveillance, as every behavior potentially can be subsumed under the large and fuzzy definitions at hand. Furthermore, the blurry concepts stand in sharp contrast to the colored scale in the right column that suggests an objective, quantified and commensurable metric ( $1=$ red: non-existent to $4=$ well developed).

Such a metric suggests objectivity and comparability (Espeland and Stevens 2008: 407) and a form of mechanical objectivity that is stripped of from subjective impressions. From the background of this discrepancy, one can assume that the institutional function of the instrument is not the purely "objective" measurement of competencies (the instrument seems to be too imprecise for this purpose) but that it has a different (additional) institutional function. As the form requires both the young person and the workshop manager to rate these different characteristics, its institutional function rather seems to be to confront the young persons with an exterior view. The form is often made relevant in one to one counseling meetings and the different assessment criteria are discussed in the light of concrete situations in the workshop. The vagueness of the description criteria is integral part if not precondition for doing so. The broad character of the items ("will to integrate, working rhythm, order and cleanliness, attitude towards the supervisor") requires the person filling in the form to select from a wide range of concrete doings and sayings and to designate them as a relevant observation for the item in question. From the view of the person to be evaluated, the choice of relevant observations must appear random and arbitrary, as nearly every behavior may be subsumed to the evaluation categories in question and re-described and re-signified under the purview of the evaluative vocabulary of the firm. 
Figure 5: Portfolio Tool: "Standardized Assessment Instrument"

\section{Evaluation du Bilan d'entrée en atelier}

Nom, Prénom :

Atelier :

$\mathrm{O}=$ évaluation du responsable
Date :

Référent :

- Faites le point sur votre expérience en atelier. Evaluez jusqu'à quel point vous maitrisez ces differentes compétences professionnelles, personnelles et relationnelles

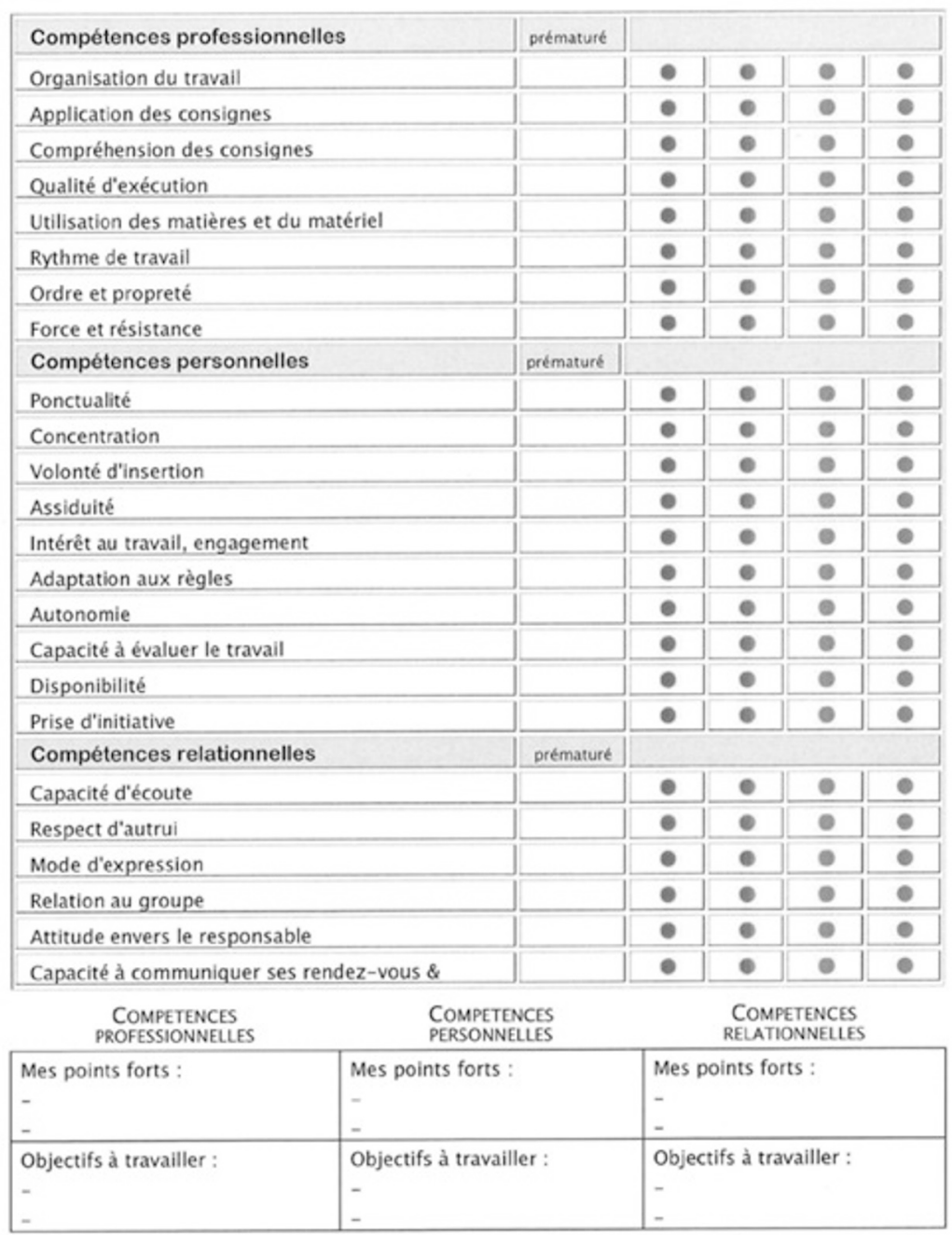


The page analyzed exemplifies a pattern that re-emerges in different places of the portfolio tool. First, a descriptive matrix similarly to a psychological "test" that displays and objectifies the space of possibilities (the standardized, colorrated items), and that classifies and positions the individual according to his "measured" dispositions. The display of these dispositions in terms of numbers (1-green to -4 red) goes hand in hand with a pseudo-mathematical transformation of observed qualities into comparable quantities. As soon as transformed into numbers, it becomes possible to display the observed qualities as if they were normally distributed. An item classified red implies that this item is "lower" than normal, that it is less well developed than the average. The different competence domains (as well as the numbers 1-4) constitute an epistemic horizon, a matrix that is the precondition for the valuation of individuals within that specified test. In a second step, this has a potential impact on the self-interpretation and the self-understanding of a person. Once a person is classified, the person potentially begins to understand oneself as a person of "that type" (for instance a person with a low ability "to follow the instructions". The person understands oneself within the epistemic horizon of the test. This process is subtle, as even when a person does not agree with the classification, the epistemic horizon still remains potentially intact, and is the background for the scrutiny of judgments and evaluations. Third but not least, the test (and the underlying evaluative matrix) has itself the potential to bring into being the personal characteristics it is supposed to measure. Persons are "interactive kinds" (Hacking 2004) which means the categorizations and classifications do something with them and to them. Persons are - once the epistemic matrix established - acting under that description. Just as Reay and Wiliam put it in their analysis of SAT-Tests in the UK, the evaluative practices at the SeMo aim at the "construction of identity through assessment" (Reay/Wiliam 1999: 343). During this process, behavior is re-signified in institutionally circumscribed ways: While behavior of peer-group related youthful insubordination may often be tolerated in a school context, it becomes a "red" mark in the field "adaptation to rules" in a work context as it is re-interpreted as lack of respect from authorities.

\subsubsection{Biographical Self-Scrutiny and the Continual Limitation of the Space of Possibilities}

While the first part of the portfolio mainly seems to address youngsters as individual choosers of their professional future that have to pursue a process of selfexploration in order to determine what individual characteristics they dispose of, part two and three of the portfolio introduce, forms of biographical self-scrutiny and patterns of reflexive self-evaluation that -little by little - link these individual characteristics to the space of institutional possibilities. After having gained "objectified" knowledge on own characteristics, young people are invited to reflect on 
the implications of that knowledge for their subjective future-oriented self-construction and - particularly in part three - for their structural possibilities. The limitation of structural possibilities (e.g. what possible jobs enter the larger field of envisioned futures) does not happen in a prescriptive, stipulative way - nobody tells the young persons that they imperatively should choose this or that apprenticeship. Rather, the structure of the portfolio-tool as well as of the instruments strive towards the subjective incorporation of structural limitations. The adaptation of the "possible" to the probable" (Bourdieu 1990), the coupling between what you "want" and "what you can get" operates through a process of textually-mediated self-formation. The "pedagogies of expertise" (Rose 1998: 93) spell out the space of the possible, the young persons align their self-scrutiny to these categories: "as I am this or that kind of person, I might consider choosing this or that job". As Rose puts it:

"Governing in a liberal-democratic way means governing through the freedom and aspirations of subjects rather than in spite of them. The possibility of imposing 'liberal' limits on the extent and scope of 'political' rule has thus been provided by a proliferation of discourses, practices, and techniques through which self-governing capabilities can be installed in free individuals in order to bring their own ways of conducting and evaluating themselves into alignment with political objectives" (Rose 1998: 155).

One example of the continual limitation of the space of possibilities is the boxes that are displayed on the bottom of the Instrument (see figure 5). Here the young person is asked to write down his strengths and his weaknesses ("points to work on") for each domain (professional competencies, personal competencies, relational competencies). In sharp contrast to the pre-given, standardized likert-scaled items on the list, the form keeps an empty space for a hand-written note by the young person. As there is limited space, the young person will necessarily have to choose one or two strengths and weaknesses from the list and write them down. The requirement to choose among the list implies that the person scrutinizes the list of items first and prioritizes it by himself. The instrument invites the young person to apply the descriptive categories of the epistemic matrix of the instrument into his own self-scrutiny and to align and synchronize the classifications of the instrument with his own self-understanding. In the context of the SeMo, this selfscrutiny gets institutionalized on a regular basis - as such, youngsters are called - in the process of self-exploration that the portfolio document deems to foster, to re-evaluate how they are faring after one month of participation ("Assess, after one month of participation in motivational semester. Think and evaluate to what extent you master these different professionals, personal and relational competen- 
cies"). As such, the first part of the Portfolio concludes with an overall synthesispage in which the young person should "choose from the different forms that you have completed" and to describe "my three biggest qualities", my "strong points", "what I know to do well", but also "my weaknesses".

\subsubsection{Linking the Biographical to the Structural: Learning to Describe Oneself in the Evaluative Vocabulary of the Labor-Market}

The third part of the portfolio to be done during the second and third month of participation includes a "inventory of dream jobs" ("list three professions that you dream of to exercise") an inventory of realised personal and professional activities ("list your professional experiences, internships, babysitting, sport, clubs, and associations. Evaluate to what extent you liked them and say why"). The young people are invited to think about their future ("Where do I see myself in five years - what is important to me") and are demanded to think about what they do or don't like in their potential future job. Participants fill a standardized interest test which leads to a "personality profile" with different "factors of interests" and which then are connected to different professional domains. This part of the portfolio resumes in a synthesis in which young people are demanded to fix up to five occupations that they want to explore. The third part invites the young participants to "starting from your experiences, evaluate to what extent the jobs you have chosen are realizable". Young people are invited to explore if a chosen job "is made for them" (green) "could eventually convene under specific conditions", or "is not for me" (red). Hereby, they are required to take into account their "school assessment" their "competency assessment", their "internship certificates", information sheets on the profession in question, and so on. For each profession, young people are asked to respond to the following questions: "What kind of work involves this job? What do I have to be good at in order to do this job? What are the conditions of admission? What are principle school branches for such an apprenticeship?".

The fashioning of a "viable" future self, of a biographical plan that can withstand the evaluation criteria of employers thus passes through justifying his own preferences, through a sort of guided self-exploration - a work on oneself that leads to the formulation of one's own desires. The realization of these different tests results in an "individualized integration agreement", In which the young person is demanded to "planify, together with the counselor, based on the assessments, the action plans, and the Interviews the objectives that allow the realization of your project" (Portfolio, part 4). These objectives, each provided with a precise date of enactment, a deadline, means and indicators ("proofs") of achievement, are then signed by both the young person and the counselor. 